\title{
EL PROYECTO DE UNA CIUDAD ILUSTRADA PARA AMÉRICA. EL DISEÑO DE RIOBAMBA (ECUADOR)
}

\author{
Jesús PANIAGUA PÉREZ \\ Universidad de León
}

Uno de los últimos proyectos urbanos realizados en América fue el ejecutado por el francés Bernardo Darquea y Barray, ilustrado que había trabajado en España, en el proyecto de nuevas poblaciones de Sierra Morena y Andalucía, a las órdenes de don Pablo de Olavide y que había mantenido relaciones con Campomanes, Aranda, Muzquiz, Jovellanos y con casi todos los grandes reformistas del momento, que dejaron en él una profunda huella, que se apreciará, sobre todo, en sus actividades americanas.

\section{LA ACTIVIDAD DE BERNARDO DARQUEA ANTES DE PASAR A LA AMÉRICA ESPAÑOLA.}

Este hombre, francés de origen, había nacido en la localidad de Bagnères, donde conoció a don Pablo de Olavide, con el cual se vino a España para asentarse en Madrid. Su carrera de funcionario la iniciaba en diciembre de 1764 en la contraloría general de la real casa, capilla y cámara del rey, en la que permanecería hasta el 22 de junio de 1767 (AGI, Quito, 383). En la fecha mencionada se trasladó al sur de España para ocupar la secretaría de la Superintendencia General de las Nuevas Poblaciones de Sierra Morena y Andalucía, cargo en el que se mantuvo hasta su salida para América, a pesar de haberse visto implicado en el proceso inquisitorial de Pablo de Olvide y todo lo que ello supuso. Aunque debió mantener una estrecha relación con los arquitectos y urbanistas de la corte, es a partir de ese momento cuando nuestro hombre comenzó a desarrollar trabajos directamente implicados con asuntos de planificación urbana. Así, colaboró con Olavide, encargado de interpretar el Fuero de Población redactado por Campomanes y de establecer la localización de las poblaciones. Fue entonces cuando Darquea se familiarizó con los asuntos de urbanismo y arquitectura y cuando debió conocer múltiples planos y proyectos de manos de los ingenieros que colaboraban en el tema, como el José Branly o el francés Simon Desnaux; de este último se piensa que pudo diseñar el núcleo de algunas poblaciones (OLIVERAS, 1998: 115), amén de que había desarrollado anteriormente algunas tareas en Guatemala como capitán de ingenieros. Sin embargo, no debemos olvidar sus probables contactos con Sabatini mientras permaneció en Madrid y la influencia que pudo ejercer sobre él el arquitecto italiano.

A finales de 1776 se vio implicado en el proceso inquisitorial de Pablo de Ola-

Polígonos, no 9, 1999, pp. 145-165. 
vide, al que trató de ayudar por todos los medios y, como consecuencia, fue detenido en abril de 1777 , en que se inició su causa, que concluiría con la reclusión durante unos meses en el convento de La Salceda.

El 31 de julio de 1778 se le expidió el permiso para embarcar hacia América y el 22 de agosto de ese año se le nombraría secretario de la visita que debía hacer don José García de León y Pizarro, manteniendo su antiguo sueldo de 1000 pesos mensuales. Mantuvo aquel cargo hasta el 27 junio de1781, en que se le nombró comisario provisional de Guerra, lo que le obligaría a hacer diferentes viajes por los territorios más conflictivos de la Audiencia (AGS, Secretaría de Guerra 7704,16-1). Luego recayó en él la dirección de la comisión que debía revisar los cacicazgos de Riobamba y otros asuntos de la real hacienda, lo que desarrollo con tanto celo que se le llegó a prometer un puesto de relevancia en alguna administración colonial (AGS, Secretaría de Guerra 7075,17-1).

Sucedió entonces el famoso terremoto de 4 de febrero de 1797, en que quedaron destruidas varias poblaciones, entre ellas las ciudades de Ambato y Riobamba. Como el corregidor del primero de estos lugares se mostró ineficaz ante los hechos, Darquea sería nombrado como su sustituto y tomaría posesión del cargo el 17 de julio de ese mismo año. Su nuevo destino iba aparejado al de administrador de rentas de la jurisdicción. Mantuvo aquellos quehaceres, de forma interina, hasta su muerte, acaecida en 1805. En todo aquel tiempo fue elogiado por los sucesivos presidentes de la Audiencia y por la población de su jurisdicción, especialmente del barón de Carondelet (AGI, Quito 383). Con anterioridad, en 1801, los vecinos de Riobamba pedían que se le diese también su corregimiento, donde podría servir como Arco Iris de la paz (AGI, Quito 252-71).

Fue en Ambato donde tuvo que demostrar por primera vez sus dotes de urbanista, sin el apoyo de un grupo de especialistas. Había que levantar la villa sobre sus cimientos, lo mismo que muchos de los pueblos de la jurisdicción, donde habían muerto hasta 5909 personas (AGI, Quito 403). Por todo eso, cuando llegó a su destino, manifestó que "ya no existía, sino un esqueleto o cadáver" (AGI, Quito 252). Pero como el problema afectaba a todo el territorio, una vez dadas las primeras disposiciones, salió a visitar la destruida provincia, donde se emprendieron toda una serie de trabajos públicos que permitieran el movimiento y el desarrollo interior de la misma, tales como puentes, molinos de agua y caminos (AGS, Secretaria de Guerra 7704, 16-1).

El 26 de septiembre de 1797 informaba de lo ejecutado al presidente interino. Tenía ya muy compuesto el camino real, listos tres molinos, elevados puentes en Chinintagua y sobre los ríos Mocha, Pachanlica y Pasa, además de uno provisional en el río Ambato, para el paso de Quisapincha, al mismo tiempo que se estaba construyendo el definitivo; otro provisional se había construido en Guapente, que facilitaba el tránsito con La Tacunga, también mientras se elevaba el definitivo(AGI, Quito 252). Además de aquellas construcciones había dado providencias para reunir a los moradores que carecían de casa en la que poder vivir y para hacer transitable el territorio. Todo ello le obligó a dejar a un lado otros asuntos de los que debía ocuparse, como la explotación de la canela del oriente (AGI, Quito 383)

Sin olvidar el resto del territorio de su jurisdicción, parece que Bernardo Darquea puso especial interés en la ciudad, cuyo trazado se debió a sus desvelos. Des- 
graciadamente la ciudad actual corresponde a una nueva reconstrucción tras otro terrible terremoto del presente siglo, por lo que no podemos hacer apreciaciones muy precisas sobre su proyecto.

Sabemos por algunos informes de que disponemos, que Ambato, siguiendo la línea tradicional de muchas ciudades hispanoamericanas, fue trazada a cordel, en torno a una plaza mayor y complementado todo ello con algunas plazoletas, planificación que ya estaba diseñada el 26 de noviembre de 1797, cuando informó a la Audiencia de sus trabajos (AGI, Quito 252). El mismo nos dice que se interesó por aquel trazado para que los moradores hiciesen sus casas con "orden y método". La mayor novedad tuvo que ver con la anchura con la que se realizaron las calles y que éstas contaron con hileras de sauces para su embellecimiento, cuestión que también le preocupó en las entradas y salidas de la población, con el fin, como el mismo dice, de hacerlas hermosas. Precisamente, en el borde del río nos manifiesta que mando hacer una alameda (AGS Secretaría de Guerra 7704,16-1), como se había vuelto tradicional en la época en muchas ciudades hispanoamericanas, a imitación de lo que sucedía en Europa. Las alamedas, además, eran algo esencial en el urbanismo español del XVIII, especialmente tras la llegada al trono de Carlos III, momento en el que comenzaron a proliferar en los alrededores de las poblaciones (SAMBRICIO, 1991: 217-218). En el mismo plan de embellecimiento mandó elevar una pirámide en una de las mencionadas plazoletas, como símbolo de la fama (AGI, Quito 252), amén de ordenar la preparación de los materiales para la construcción de la pila de la plaza mayor (AGI, Quito 383).

Desgraciadamente no sabemos mucho de lo que suponemos fueron las construcciones más relevantes, como las iglesias y edificios públicos, que él abordó con especial interés, pero de los que solo nos ha quedado alguna mención, como su interés por la construcción de la capilla de San Miguelito y de la iglesia matriz de Ambato, así como las de otras localidades; todo ello sin olvidarse de la construcción de algunos edificios públicos, como la cárcel (AGI, Quito 252).

Las labores de reconstrucción de la villa, bajo su supervisión, se hicieron de una forma bastante acelerada, hasta el punto de que muchos vecinos manifestaban su incredulidad por la rapidez con la que se avanzaba (AGS, Secretaría de Guerra 7704,16-1).

Pero la infraestructura de la nueva población fue también una de sus preocupaciones esenciales. Junto con la planificación de la ciudad, el agua se convirtió en una obsesión de nuestro hombre, por todo lo que su aprovisionamiento implicaba. En poco tiempo, pues, se puso en funcionamiento un molino para abastecer a la población, el cual distaba más de cuatro leguas y pasaba por una zona árida, por lo que su agua era aprovechada por algunos habitantes para sus cultivos, cuando en realidad se necesitaba en las obras de reconstrucción de la ciudad. Debido a que con ella no era del todo posible satisfacer las necesidades, decidió reconstruir la acequia de Miraflores, que tradicionalmente surtía la villa (AGS, Secretaría de Guerra 7704,16-1).

El desarrollo de la nueva localidad sufrió, pues, un acelerado avance bajo su mandato. Así, en 1804, el barón de Carondelet nos relata que había hermoseado la población con paseos, fuente, arboledas en sus calles, etc., haciéndola una de las más alegres y amenas de la provincia. Sin embargo, por aquellos años se seguía 
con los proyectos de llevar aguas que "pondrán las tierras muy fértiles" (AGI, Quito 383).

Todas aquellas realizaciones las había llevado a cabo sin gravar al vecindario y atrayéndose las simpatías de todos, por lo que se le consideraba "dotado de grandes talentos y de las mejores disposiciones para gobernar un pueblo". Pidieron los de Ambato, por tanto, que se le mantuviese en su puesto, mientras los de Riobamba también le querían al frente de su jurisdicción, incluso cuando interinamente se había nombrado corregidor de aquella ciudad a Javier Montúfar (AGI, Quito 252).

\section{LOS HECHOS QUE CONDUJERON A PROYECTAR LA NUEVA CIUDAD DE RIOBAMBA.}

De los proyectos urbanos que conocemos en el siglo XVIII para Hispanoamérica, el de Riobamaba es, sin duda, el más llamativo, aunque no llegara a ejecutarse. Darquea tuvo en sus manos el sueño casi imposible de proyectar la nueva traza de una ciudad ideal, del modo y manera como la concibieron algunos ilustrados.

Riobamba había sido destruida totalmente por el terremoto de 4 de febrero de 1797. El fenómeno no tenía nada de novedoso, aunque en esta ocasión los estragos fueron mucho mayores que de costumbre. Pocos años antes, en mayo de 1786, algunos temblores habían sacudido la ciudad, aunque sin causar grandes daños (VELASCO, 1981: 357-358). Las vidas humanas que costó aquel suceso, último del siglo XVIII, no pudieron cuantificarse, tal y como se manifestó en el cabildo de la ciudad, de 11 de octubre de 1797. Alegaban las autoridades municipales, que no era posible realizar aquel recuento de víctimas, puesto que muchos de los que sobrevivieron habían abandonado la zona y, además, no existían patrones de la servidumbre de la población, que era abundante en los barrios que habían sido anegados por el derrumbe del monte Cullca (AGI, Quito 384). Aun así, se elaboró una estadística estimativa fechada el 18 de noviembre de $1797^{1}$.

La destrucción total de la ciudad hizo que los vecinos tuvieran que salir de ella y se ubicaran en el cercano lugar de Cajabamba, en espera de que se tomara alguna decisión. Sin embargo, se consideró que aquél no era el lugar adecuado para la población y, por miedo a que se asentaran definitivamente allí, el presidente de la Audiencia, el 30 de marzo de 1797, prohibió usar el mencionado nombre de Cajabamba a los vecinos, debiendo mantener el de la ciudad destruida (AGI, Quito 403). Para entonces, un buen número de vecinos habían iniciado un proceso migratorio hacía otros territorios quiteños, especialmente hacia la ciudad de Cuenca (AGI, Quito 403), menos aquejada por la crisis finisecular que afectó a los territorios de la Audiencia de Quito.

\footnotetext{
${ }^{1}$ AgI, Quito 555. Existen algunos errores en la suma, que hemos corregido: Los muertos de Sicalpa suman 30 (29 según el documento), con lo cual el total de indios y mestizos suman 876; El total que nos daba el original ascendía a 2.306 muertos, cuando en realidad la suma total nos da una cifra de 2.037 .
} 


\begin{tabular}{|c|c|c|c|c|c|c|c|}
\hline Lugares & Curas & $\begin{array}{l}\text { Clérigos } \\
\text { sencillos }\end{array}$ & $\begin{array}{c}\text { Religiosos } \\
\text { Monjas }\end{array}$ & Nobles & $\begin{array}{l}\text { Blancos } \\
\text { Mestizos }\end{array}$ & Indios & Tot. \\
\hline Riobamba & & 9 & 28 & 90 & 445 & 305 & 877 \\
\hline Sicalpa & 1 & & & & 1 & 28 & 30 \\
\hline Cajabamba & 1 & & & & & 185 & 186 \\
\hline Columbe & & & & & 4 & 20 & 24 \\
\hline Guamote & & & & & & 21 & 21 \\
\hline Pungalá & & & & & 4 & 8 & 12 \\
\hline Licto & & & & & 18 & 72 & 90 \\
\hline Punín & & & & & 83 & 37 & 120 \\
\hline Yaruquíes & 1 & & & & 4 & 84 & 89 \\
\hline San Luis & & & & & 8 & 7 & 15 \\
\hline Achambo & 1 & & & 10 & 55 & 34 & 100 \\
\hline Quimiag & & & & & & 1 & 1 \\
\hline Penipe & & & & & 5 & 4 & 9 \\
\hline Guanando & & & & & 189 & 72 & 261 \\
\hline Cubijíes & & & & & 3 & 2 & 5 \\
\hline Ilapo & & & & & 2 & 10 & 12 \\
\hline Guano & & & & & 46 & 14 & 60 \\
\hline San Andrés & & & & 3 & 6 & 32 & 41 \\
\hline Licán & & & & & 1 & 16 & 17 \\
\hline Calpi & & & & & 2 & 65 & 67 \\
\hline TOTAL & 4 & 9 & 28 & 103 & 876 & 1.017 & 2.037 \\
\hline
\end{tabular}

Había quedado patente para entonces que la ciudad no podía volver a asentarse sobre su antiguo emplazamiento, lo que obligó a iniciar un proceso de elección de lugar. El 18 de marzo de 1797, el presidente de la Audiencia pidió al Cabildo información al respecto, pero alegando que el nuevo asentamiento debía realizarse en tierras de realengo o baldías y donde hubiese facilidad para abastecerse de agua; al mismo tiempo recomendaba que las construcciones se hiciesen con la precaución necesaria para evitar nuevas ruinas y desastres (AGI, Quito 403).

Los posibles lugares en los que pensó el Cabildo riobambeño fueron los llanos de Gatazo y Tapi aunque con una cierta preferencia por los segundos, en los que se hizo una inspección que resultó favorable (AGI, Quito 403). La traslación a Tapi, por tanto, ya estaba definida, aunque no existían los medios necesarios para ello, por lo que el corregidor pidió que se les perdonasen los tributos y alcabalas durante cuatro años (AGI, Quito 403). Para la erección de la nueva ciudad se pensó en nombrar a un comisionado, a lo que se opuso el fiscal oidor de Quito, el 26 de mayo de 1797, alegando la falta de medios (AGI, Quito 403). Sin embrago, el traslado quedó definitivamente aceptado el 17 de junio de 1797 (AGI, Quito 403) y, el 6 de julio, se decidió encargar a los agrimensores Mariano Oñagoitia y Miguel Ramos la medición del terreno, mientras que para la planificación se pensó en el español Francisco Espejo.

Para entonces se alzaron algunas voces contra aquella elección y comenzaron a dejarse oír los que querían la nueva población en el llano de Gatazo, capitaneados por el procurador general y sindico personero del común, Ignacio de Velasco y Unda, que consiguió inclinar las intenciones hacia sus deseos, dando como razones de peso la proximidad del agua, la firmeza del suelo, la posibilidad de aprovecha- 
miento de materiales de la antigua ciudad por su cercanía, etc. (AGI, Quito 403). El problema mayor estaba en que no era tierra de realengo, pero aun así se consideraba la posibilidad de comprar los solares sin graves dificultades.

Aquello abrió una polémica en la ciudad, que enfrentó a sus vecinos. La situación llegó a agravarse tanto, que las autoridades de Quito decidieron poner fin al asunto enviando un comisionado, para lo que se pensó en el corregidor del vecino lugar de Ambato, Bernardo Darquea, conocedor de la materia por su ya relacionada experiencia en España y por estar realizando con éxito todos los trabajos referentes a la reconstrucción de una ciudad afectada casi tanto como Riobamaba por el terremoto. No le agradó, sin embargo, al mencionado corregidor aquel encargo y trató de disculparse, incluso con misivas poco diplomáticas, pero al final no tuvo más remedio que aceptar la solicitud, presentándose ante el Cabildo riobambeño el 27 de septiembre de 1797. Allí sondeó la opinión de los habitantes y comprobó una clara preferencia por los llanos de Tapi. Pero antes de tomar una decisión definitiva, Darquea inició una inspección de ambos territorios con testigos de la ciudad, que le hicieron inclinarse por aquel lugar y de forma especial, por el llano conocido como de San Miguel (AgI, Quito 403).

Una vez comprobada la idoneidad del terreno, en el que todos estuvieron de acuerdo para el asentamiento, se hizo una misa de acción de gracias en honor de San Miguel, por haber sido en su día la elección (29 de septiembre), después de haber delineado lo que debería ser la plaza mayor de la nueva Riobamba y tomar medidas para la nueva figura del lugar (AGI, Quito 403).

La actividad y la decisión de Darquea parece que agradó a todos. Así, el 13 de octubre de 1797, el Cabildo decidió darle las gracias por su beneficioso y magnífico trabajo. En ese mismo momento se prohibía a los vecinos fabricar sus casas en Cajabamba o en la antigua Riobamba, con la obligación de hacerlo en Tapi, para no consumir dinero en habitaciones provisionales, de modo que, quien contraviniese aquella disposición, debería pagar una multa de 4 pesos para las obras públicas o, si era un indio, debería trabajar en ellas durante un mes (AGI, Quito 384). Ahora, el traslado solo dependía de la aprobación del gobierno superior y de disponer de los medios para el traslado de una población empobrecida (AGI, Quito 384). Por todo ello, Darquea, el 11 de octubre de 1797, solicitó al presidente de la Audiencia que los caciques y gobernadores de la jurisdicción enviasen a sus indios para el transporte de los escasos materiales que la población tenía en su asentamiento provisional. Aprovechando su actividad anterior con los caciques de la región, había conseguido que éstos manifestaran su disposición a ayudarle, por lo que encargó del traslado a don José Larrea, amén de que se comenzó la construcción de una acequia que había prometido costear el vicario José Manuel de los Reyes. Finalmente, el presidente firmó el oficio de traslación de la ciudad de Riobamba el 10 de noviembre de 1797 (AGI, Quito 384), aunque no se haría hasta fechas bastante posteriores.

\section{EL PLANO DE LA NUEVA CIUDAD.}

El proyecto de Darquea para la nueva población de Riobamba era bastante diferente a los que se habían realizado en Sierra Morena y Andalucía (LÁmINA 1). 
Tampoco respondía al modelo que había utilizado para reedificar la capital de su corregimiento, Ambato, en que se mantuvo el plano de cuadrícula, tradicional de las ciudades hispanoamericanas, aunque se había recurrido a alamedas y a calles más anchas y arboladas, de acuerdo con el espíritu ilustrado de nuestro hombre.

Darquea, siguiendo las nociones de los ilustrados, pretendió diseñar una ciudad de acuerdo con las ideas que prevalecían en el momento. El proyecto, por tanto, parece responder a la intención ilustrada de llevar la felicidad a los habitantes de aquella población tan maltratada por la naturaleza. Ese ideal de felicidad, que Jovellanos consideraba que era el estado de abundancia y comodidades que debe procurar el buen gobierno a sus individuos (JOVELLANOS, 1984: 443), había favorecido el desarrollo de las utopías, como la de Sinapia, atribuida a Campomanes (AVILÉS: 1975). La ciudad era, además, el campo mejor abonado para la realización de aquel pensamiento utópico, pues no se podría hablar de felicidad de los individuos, si no era poniendo a éstos en relación entre sí, por lo que dicha felicidad era considerada como un asunto público, ya que necesitaba un número considerable de personas para pasar a ser el ideal de la felicidad general (MARAVALL, 1991: 168). Por tanto, esa felicidad común parece ser la que buscó el corregidor con su nueva planificación.

El proyecto de nuestro ilustrado se hizo en los últimos días de septiembre de 1797, durante su visita al los llanos de Tapi, cuando se dice que había delineado la plaza mayor y tomado las medidas para la nueva figura del lugar (AGI, Quito 384) (LÁMINA 2). En octubre del mismo año, el fiscal de la Audiencia de Quito ya tenía en sus manos el diseño y ponía los reparos pertinentes para su ejecución. Esto nos hace pensar que el plano, fechado en 1798, que es el que hoy conocemos del Archivo del Municipio de Riobamba, debe ser una copia más tardía del original o, simplemente, la puesta en limpio de los primeros dibujos y esquemas (LÁMINA 3).

Es la originalidad lo que prevalece ante nuestros ojos, si lo comparamos con la mayor parte de las ciudades hispanoamericanas, incluso de las diseñadas en el siglo XVIII.

El modelo es el de una ciudad radial, en la que se mezclaban varios conceptos de los que hablaremos en este apartado. Pero las autoridades de la Audiencia de Quito no estaban dispuestas a romper con la tradición del damero y, frente a lo proyectado por Darquea, pidieron que la planta se hiciese según la ley I, título VII, libro IV de las Leyes de Indias, en la que se decía:

"Y quando hagan la planta del lugar, repártanlo por sus plaças, calles y solares, a cordel y regla, començando desde la plaça mayor y sacanco desde ella las calles a las puertas y caminos principales, $y$ dexando tanto compás abierto que, aunque la población vaya en gran crecimiento, se pueda siempre proseguir y dilatar en la misma forma" (AGI, Quito 384).

Por tanto, el trazado radiocéntrico de Darquea no se consideraba conveniente para la nueva población. El informe del fiscal aludía también a la ley VIII, en lo que se refiere a la ubicación de los monasterios e iglesias, que deberían hacerse en plazas menores, donde se creyese conveniente (AGI, Quito 384). 
Lámina 1. Proyecto definitivo de la ciudad de Riobamba.

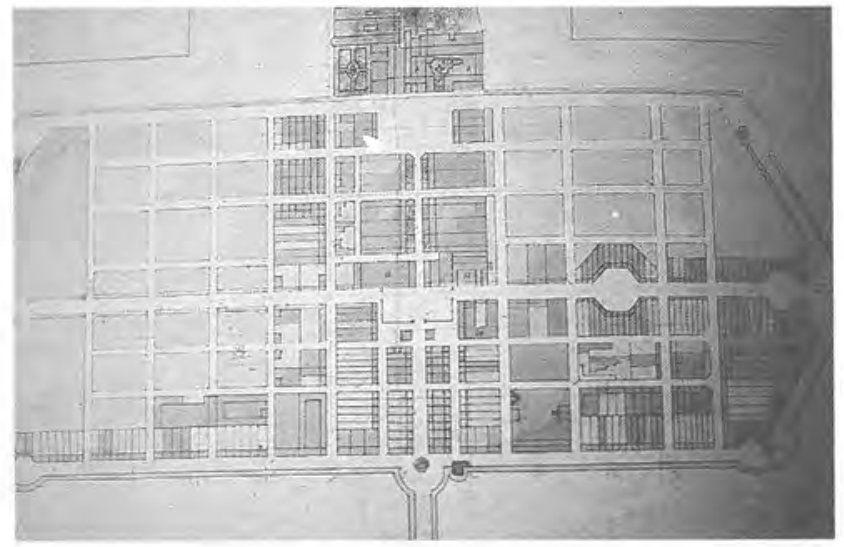

Lámina 2. Proyecto de Riobamaba. Bernardo Darquea (1798). Plaza Mayor.

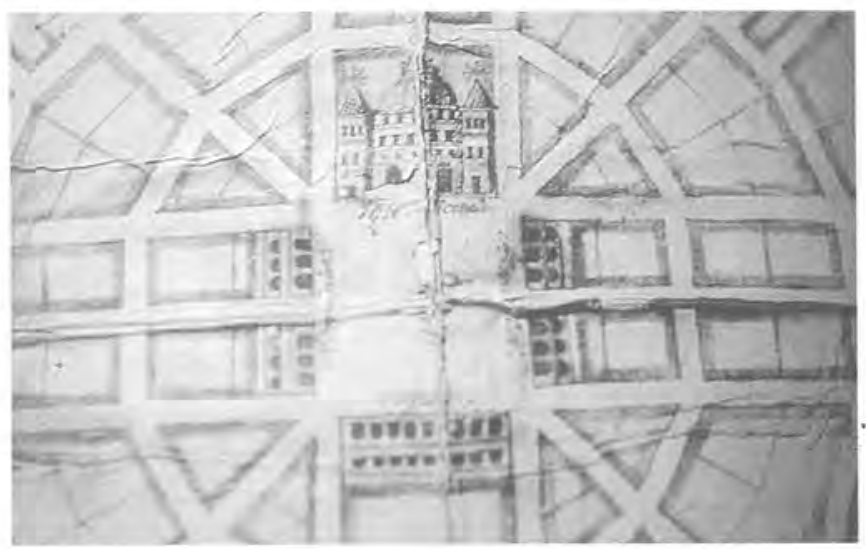

Lámina 3. Proyecto de Riobamaba. Bernardo Darquea (1798).

Lámina 4. Plano definitivo de la ciudad de Riobamba.
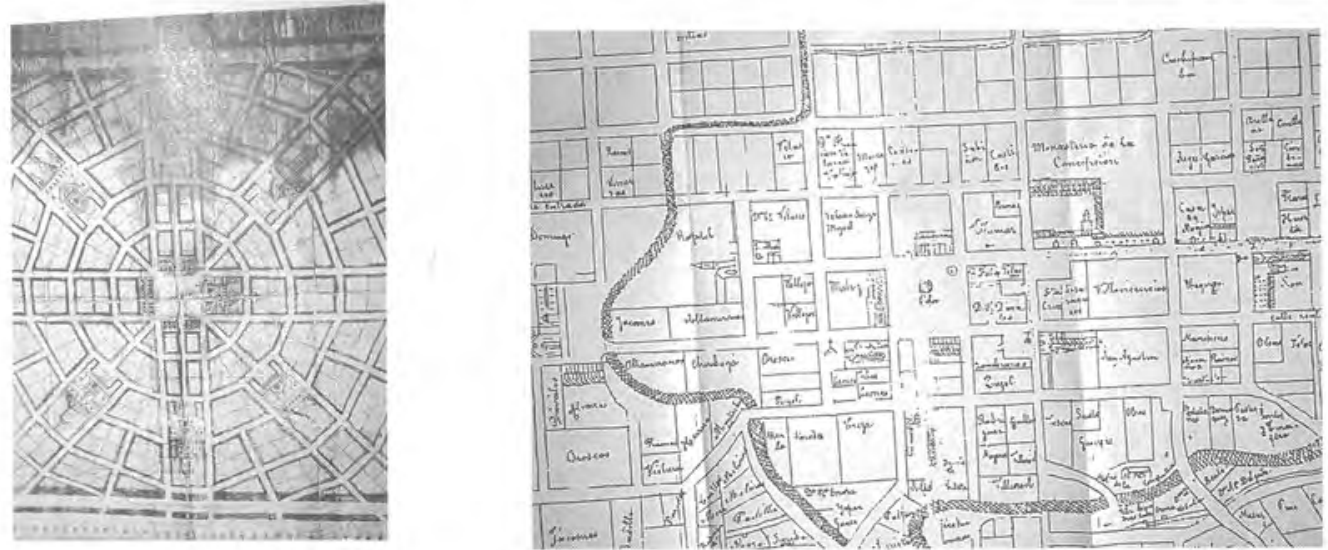
Después del informe del fiscal, la Audiencia emitió otro, el 3 de noviembre de 1797, en el que ratificaba lo expuesto anteriormente, diciendo que "aunque el mapa o diseño formado por don Bernardo Darquea para la planificación de la villa de Riobamaba en el sitio nombrado Tapi, es agradable a la vista" no se podía eludir "lo expresamente dispuesto por leyes municipales en el título siete, libro cuarto". A la postre, la Audiencia ratificaba su decisión del acuerdo de 27 de mayo, antes de que el proyectista tuviese nada que ver con aquella planificación, y que había mandado ejecutar el presidente el 8 de junio; es decir, prevalecía la idea de lo expuesto en las Leyes de Indias. Por tanto, la plaza debía ser cuadrilonga (el largo debía ser, al menos, una vez y media el ancho) y las calles a imitación de las de Quito o de cualquier otra ciudad de América, o de las más principales de España, debiendo practicarse de acuerdo a la ley IX de la Recopilación. Además, de esa plaza saldría una calle porticada por el centro de cada costado, y dos por cada vértice de la plaza. Se mezclaban, pues, las calles axiales y perimetrales.

Ante aquella oposición de las autoridades superiores de Quito, el plano de Darquea no se llevó a efecto, pero tampoco lo que expresamente ordenaban las Leyes de Indias, toda vez que el ejemplo a imitar era el de la propia ciudad de Quito, con lo cual la plaza se hizo cuadrada y las calles axiales se eliminaron, quedando, como en casi todas las ciudades americanas, las calles perimetrales. Tampoco la simetría que presentaba el proyecto original, en lo que se refiere a la ubicación de los principales edificios, fue tenido en cuenta (LÁmINA 4).

La ciudad que se construyo siguió el plano tradicional de casi todas las ciudades hispanoamericanas anteriores y posteriores a las Nuevas Ordenanzas de Población de Felipe II. Se volvió a reproducir la monotonía de un damero casi perfecto en el que las plazas se consiguieron rentranqueando algunas esquinas de las manzanas, salvo la plaza mayor que, como era tradicional se consiguió por medio de la eliminación de una de esas manzanas. De nuevo volvemos a encontrarnos ante una ciudad abierta, sin límites para su expansión y que poco tenía que ver con el proyecto de nuestro ilustrado.

Pero volviendo al plano de Darquea (LÁMINA 5), éste mezclaba un sistema de calles radiales y perimetrales, organizado todo a partir de una plaza cuadrada y con un contorno de la urbe idéntico a escala. Dentro del gran cuadrado en el que se inscribía el conjunto, se insertaban cinco polígonos de diferentes lados, a pesar de la apariencia de similitud que ofrecía. Los dos polígonos más cercanos a la plaza disponían de doce lados; los dos siguientes duplicaban el número de los mismos; existía, además, un último polígono, incompleto por la necesidad de adaptarse al contorno cuadrangular. Los lados de los polígonos, como dijimos, no eran iguales, produciéndose una alternancia inversa; los más cercanos a la plaza mayor tenían más largos los lados que correspondían a las paralelas de las calles perimetrales, mientras que en los polígonos más alejados se producía la sensación inversa. El autor consiguió esto introduciendo calles perimetrales, laterales a las iglesias, que se ubican en el inicio de los polígonos de más lados y cuyas fachadas daban a las calles axiales que salían de la plaza. Esta combinación permitía a Darquea establecer solares que, si no eran idénticos entre sí, al menos tenían una escasa variedad en sus medidas, exceptuando los triángulos que se generaban en las esquinas de la plaza. 
Lámina 5. Recreación del proyecto de Riobamba de Bernardo Darquea (1797).

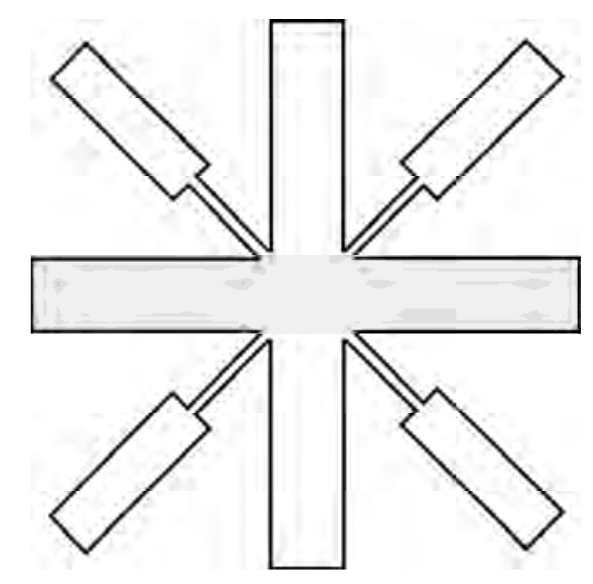

Plantas muy semejantes en la época, aunque en ciudades de contorno poligonal, fueron las que se planearon en la Rusia de Catalina II, como Bogorodzik (1778) y Lucha (1781); también en Rusia podemos ver una cierta similitud en una parte del plano de San Peterburgo, realizado en tiempos de Pedro el Grande (LÁmINA 6). Tampoco estaba lejana esta planificación a los proyectos de Sabatini para algunos de los jardines del entorno del palacio real de Madrid. Quizá uno de los planos de mayor similitud con el esquema de esta planta esté en el diseño que para la Biblioteca Pública de París realizó Pierre-Adrien Paris, en 1773.

Darquea, en este proyecto, del que hasta ahora no conocemos sus propios comentarios, parece estar mezclando cosas muy diferentes. No olvidemos que estamos ante un hombre que había conocido muy directamente a los ilustrados, algunos de ellos utopistas, como Campomanes y, si cabe, el propio Olavide; además, había estado muy en contacto con ingenieros militares, españoles y extranjeros, amantes del orden y de una rígida simetría; que sus orígenes eran franceses; y que, durante su estancia en la corte, se habría relacionado con artistas italianos y españoles, representantes del último barroco y del neoclasicismo.

En cuanto a precedentes más antiguos, casi estamos ante las visiones de Cesariano de la rosa vitrubiana de los vientos (LÁMINA 7) o del homo ad circulum, sin olvidar algunas planificaciones como las de Neubreisach o Philippeville e, incluso, alguna de las proyecciones de Serlio (LÁMINA 8). Pero quiza el precedente más exacto debamos buscarlo en la ciudad de Palmanova, en la antigua república de 
Lámina 6. Plan de San Petersburgo (Rusia), por J.B. Le Blond (1717).

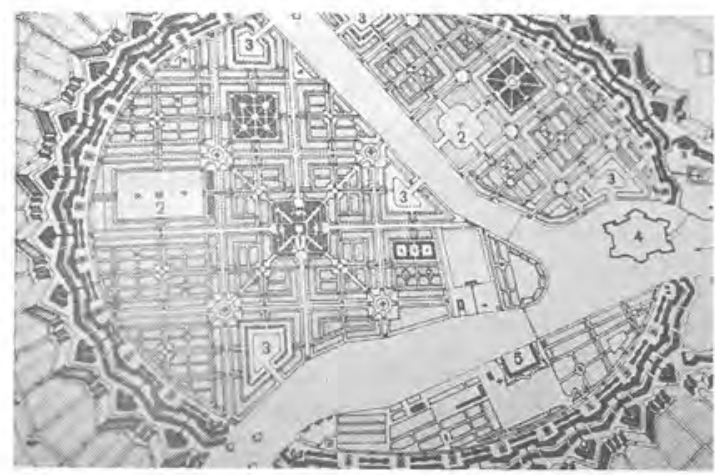

Lámina 7. Cesariano. La ciudad de Vitrubio. Siglo XVI.

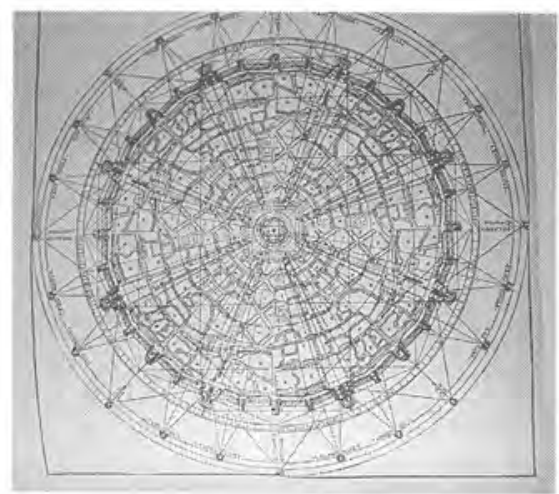

Lámina 8. Serlio. Proyección. Siglo XVI.

Lámina 9. Plano de Palmanova, según Braum y Hogemberg. Siglo XVI.
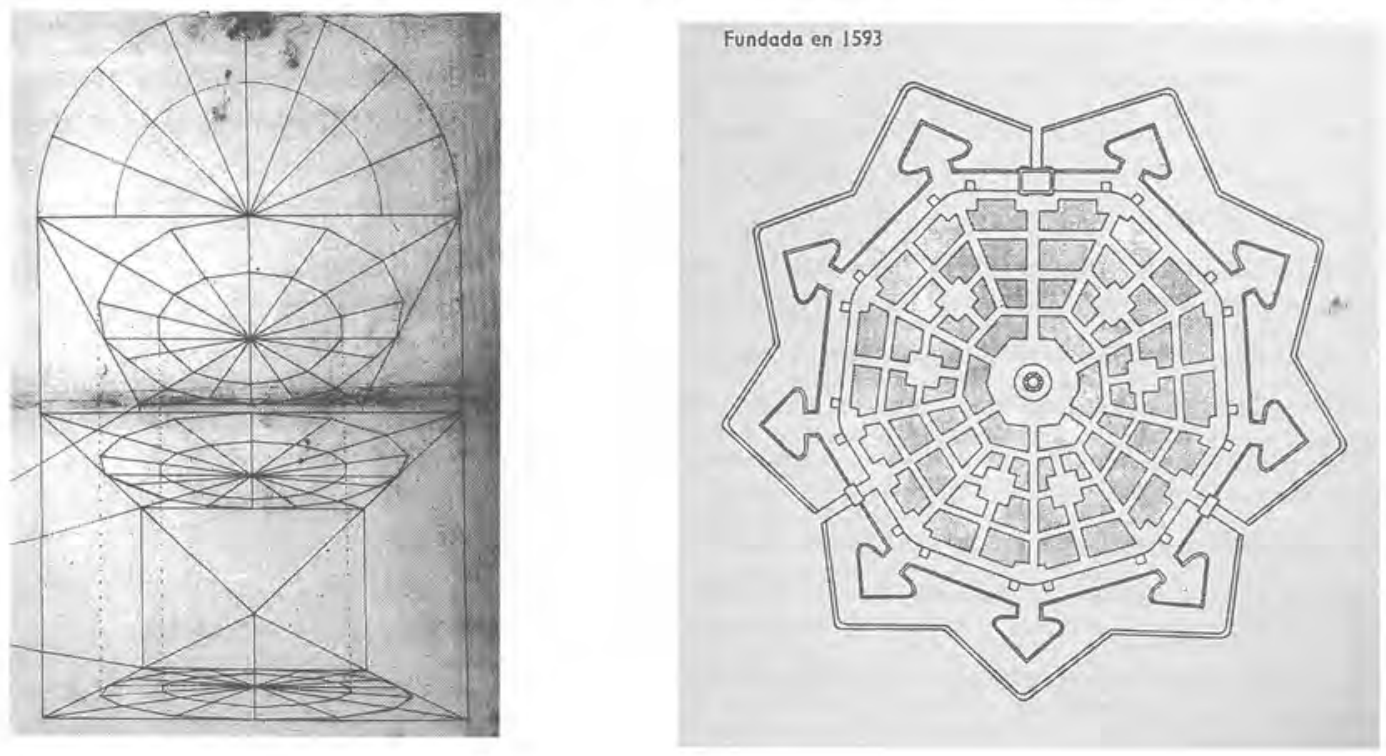
Venecia. La semejanza entre Riobamaba y la ciudad italiana es asombrosa, a pesar de que ésta última tenga planta eneagonal, lo mismo que su plaza (LÁMINA 9).

Sin embargo, en ambas nos encontramos con los solares trapezoidales y con calles radiales que se interrumpen antes de llegar a la plaza; incluso en ambas es evidente la equidistancia entre las plazas, que en el caso de Riobamaba responden a los atrios de las iglesias. Es evidente que también existen claras diferencias, como el aspecto fortificado de Palmanova, debido a que surgió como fuerte para defender la ciudad de Venecia, mientras que Riobamba no tuvo nunca intención de proyectarse con tales fines, por lo que sus límites son hermosas alamedas que, de alguna forma, nos recuerdan las ciudades amuralladas en su plano, sin que en la práctica ambas cosas tuviesen nada que ver.

En todos esos precedentes la simetría era un punto esencial, como imagen del orden que los ilustrados siempre quisieron dar. Y mientras en las ciudades hispanoamericanas la primitiva simetría, cuando la hubo, se fue rompiendo con el paso del tiempo (ejemplos claros son en el propio Ecuador las ciudades de Quito y Cuenca), en el plano de Darquea tiene visos de continuidad, al plantear una ciudad cerrada, con lo que también queda exaltado el principio de unidad, en que la parte esencial del espacio urbano resulta inamovible.

La ciudad de Darquea se organiza en torno a unos ejes que forman una cruz potenciada (LÁMINA10). La cruz, en el mundo urbano, nos remite a ideas cristianas, en parte retomadas del mundo clásico, pero que en el mundo hispánico exaltaría Eiximenio a finales de la Edad Media, aunque otros autores con anterioridad, como San Agusrín, habían potenciado la idea de la Ciudad de Dios.

La visión cruciforme en el entramado urbano puede hacernos pensar, también, en la visión del Templo del profeta Ezequiel, tal como se aprecia en la Biblia de Sebastián Castellion, de 1551 (LÁMINA11). En este último sentido y más cercana en el tiempo está la planificación de la ciudad de Servigliano, realizada por Virginio Bracci, que se construyó entre 1772 y 1796 . Pero, además de todo esto, es muy probable que en Darquea esté funcionando con la idea de la cruz como protección de la ciudad, especialmente en un lugar como Riobamaba, que se había visto asolado en varias ocasiones por las catástrofes naturales. No olvidemos que el símbolo de la cruz, como protectora, se ha utilizado entre los cristianos en casi todo lo imaginable. Así pues, la simetría, como idea de unidad que puede remitirnos a Dios, esta muy acentuada en los planos de Darquea, pues se plantea desde todos los ejes y ángulos. La forma de cruz con potencias de Riobamba no fue, ni mucho menos, única en el mundo hispánico de la Ilustración, pues algo parecido nos encontramos en el plano que Mariano Tamarit desarrolló en 1803 para la planta de la colonia militar de Fernandina, aunque con un planteamiento general de damero; o la que elaboró en 1807 Silvestre Pérez para el puerto de La Paz; o la casi paralela en el tiempo a la de Riobamba, la de Sangüesa, de 1786, de Santos Angel de Otxandategui.

En Darquea, por tanto, estamos ante un nuevo intento de casar la ciudad cristiana con la ciudad clásica, tal y como ya lo había hecho en el Renacimiento Matteo Selvagio, en su concepción de Roma como Jerusalén, cuyo plano tiene bastante similitud, sin entrar en los detalles, con el de Riobamba. 
Lámina 10. Esquema de los ejes de organización de la ciudad de Riobamba, según el plano de Bernardo Darquea (1797).

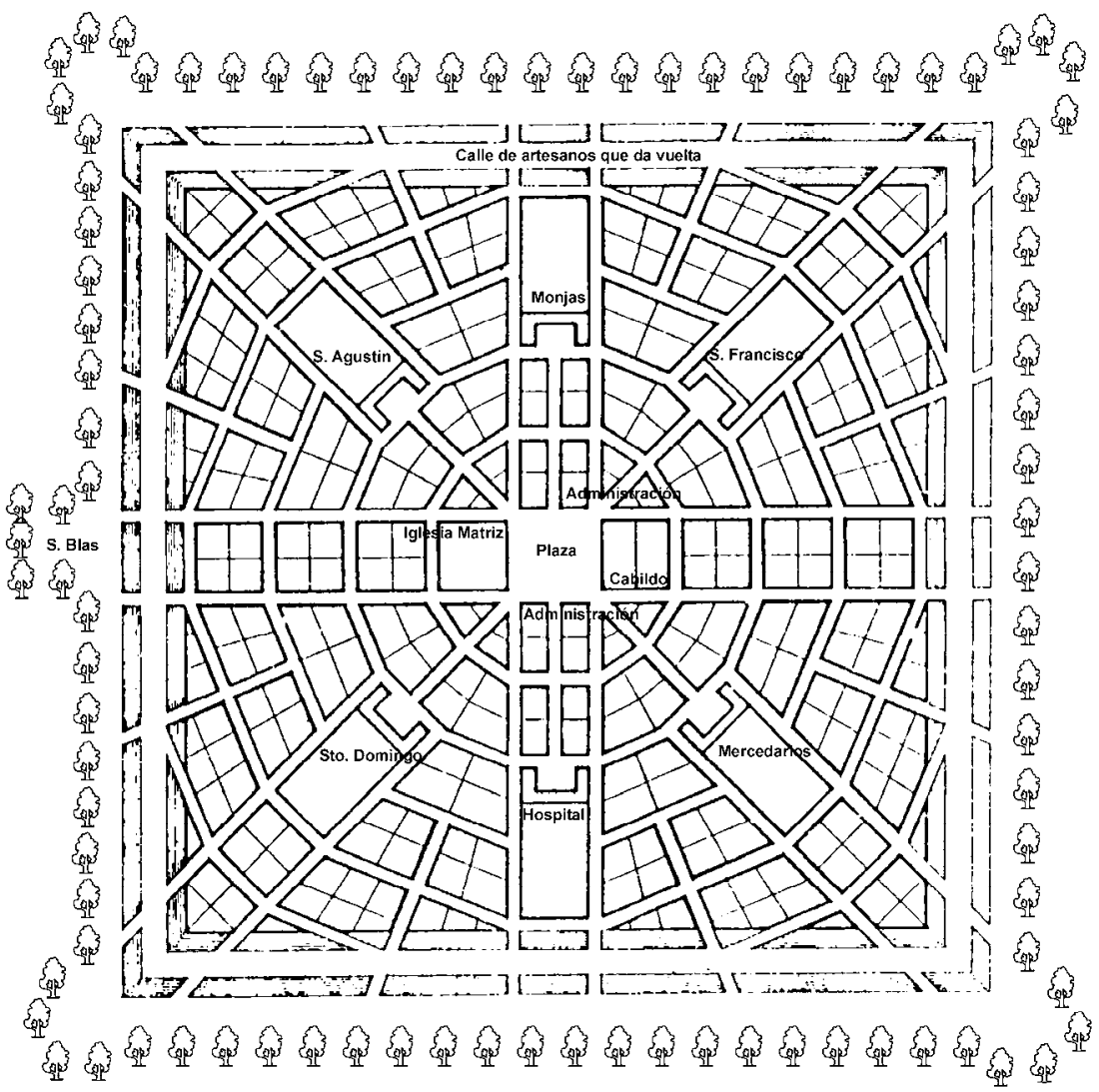

La idea cristiana de la ciudad de Darquea no solo se aprecia en la gran cruz que forma la estructura de su trama, sino que se acentúa con las cuatro potencias, en cuyos extremos sitúa las iglesias y conventos de las cuatro órdenes religiosas masculinas de la ciudad: San Francisco, La Merced, Santo Domingo y San Agustín. A ellas se debía la cristianización del territorio, convirtiéndose, por tanto, en símbolo de la fe triunfante dentro de una población que, a la postre, debería ser el espejo del territorio que controlaba su jurisdicción. Hay que añadir, además, otros dos edificios que destaca Darquea: el hospital y el monasterio femenino de la Concepción. Ambos se colocan en el brazo principal de la cruz. Hay razones prácticas para ello. Ocupan los lados extremos del eje, en solares rectangulares, lo que les permite una mayor ventilación, ya que en ambos casos la parte trasera de aquellas edificaciones quedaba abierta a los extremos de la ciudad y, además, los alejaba del probable bullicio que se podía generar en el centro. En lo simbólico, esa ubica- 
ción privilegiada puede responder a unos motivos bastante evidentes. Si la ciudad estaba concebida desde una óptica cristiana, no hay que olvidar que la caridad ha sido la virtud más ponderada por el cristianismo y el hospital es, sin duda, el mejor símbolo de esa virtud dentro del entramado urbano. En el caso del monasterio de la Concepción podríamos pensar en la protección de la mujer y en todos los atavismos que ello encerraba en la época, especialmente, si consideramos que la entrada en la vida monacal femenina iba unida a todo un entramado de relaciones sociales de privilegio.

La religión, siguiendo la tradición del mundo europeo, provocó una jerarquización urbana, en la que Riobamaba sería un segundo punto respecto de Quito, sede episcopal. Se convertía así en un lugar simbólico, como centro de un cristianismo militante, en el que todavía se veía inmersa la iglesia católica de la antigua Audiencia de Quito.

No debemos tampoco dejar a un lado la influencia que la arquitectura militar había podido jugar en el proyecto de Darquea. Él, como ya manifestamos, había estado muy vinculado en Andalucía a los ingenieros militares y de ellos pudo haber aprendido muchas cosas, al margen de que pudieran haberle mostrado gran cantidad de planos y tratados, que le ayudaron a familiarizarse con el mundo de los proyectos urbanos. En la nueva Riobamba se puede apreciar cierto carácter militar en el diseño, aunque, evidentemente, hay otras cosas que lo contradicen, principalmente el gran número de accesos de que debería disponer la urbe. Las similitudes del plano de esta ciudad con obras militares podemos verlas, por ejemplo, en la organización de una de las torres que nos reproduce el tratado renacentista de Francesco di Giorgio Martini (MARTINI, 1967: 258) (LÁMINA 12), en que recurre a un cuadrado central con dos ejes en cruz y con las potencias acabadas en punta de flecha. En el mundo hispánico algo parecido encontramos en el recinto cuadrado que reprodujo en su día Cristóbal de Rojas (ROJAS, 1598: 41-46).

El conjunto urbano quedaba centralizado por la plaza de forma definitiva en el tiempo, puesto que, como ya dijimos, estamos ante un esquema cerrado de ciudad. Otras poblaciones tradicionales, como Quito o Cuenca, cuyo planteamiento inicial de la plaza fue también centralizado, perdió este sentido geométrico, aunque no social, debido a las exigencias que el medio impuso en el crecimiento. Aquí, como la ciudad quedaba planificada hasta en su contorno, la centralidad no podía perderse. Sin embargo, el simbolismo de la plaza seguía manteniéndose en la tradición: el poder del rey quedaba exaltado sobre todas las cosas, aunque esto no podemos considerarlo como ajeno a la época. Esa plaza simbolizaba el poder de la monarquía hispánica, de ahí que en ella se concentrasen los edificios de la administración y la iglesia mayor; esta última sería el símbolo del patronato regio o el poder del rey sobre la iglesia de América, en un momento en que aquel poder pretendía hacerse extensivo a la iglesia española. No hay, pues, anacronismos en esa idea de lugar central, puesto que seguía respondiendo a los intereses de la casa de Borbón. Además, solo existía esa plaza, lo que acrecentaba la idea de unidad y de germen de toda la planificación; por tanto, todo se supedita y confluye en ella, incluso el mundo exterior. Si a ello añadimos los ejes que se irradian hacia las iglesias de las distintas religiones tendremos un panorama total, una escenografía que puede resultar barroca, pero que tiene visos de modernidad. Frente a la ciudad hispanoame- 
ricana tradicional, la unidad ahora es plena, en una especie de organicismo en el que las partes no se conciben fuera de la totalidad. Las ciudades de las posesiones españolas de ultramar mostraban su unidad, de forma esencial, en la utilización del plano de damero, pero las diferentes partes quedaban aisladas entre sí. Por ejemplo, en Quito, poco tenía que ver el conjunto en el entorno de San Francisco con el entorno de San Agustín; ni siquiera las iglesias, como centros de atracción, tenían confluencias comunes. El damero hispanoamericano creaba espacios que, aunque cercanos en cuanto a la distancia, mentalmente estaban alejados entre sí; por el contrario, en el plano radiocéntrico de Darquea, se tendía a vincular todo el espacio con la plaza mayor. Estamos, probablemente, ante el orden por el que abogaba Milizia, como conexión entre las partes, entre las cuales tiene que haber una principal sobre todas las demás y que, en el plano de Darquea, sería la plaza mayor.

El modelo de plaza que se utilizó fue el porticado, como se hizo en otras muchas de la época en España, de acuerdo con lo que correspondía a una ciudad centro de una jurisdicción, reflejando la idea simbólica de protección que cumplían estos espacios (LÁMINA 13). Las iglesias de las diferentes órdenes religiosas, fuera de la plaza, también generaban unos pequeños espacios en su frente, a los que difícilmente podemos considerar como "plazas", respondiendo más a la idea de los atrios, aunque con una concepción diferente a la que tradicionalmente habían tenido en muchos territorios de América, donde, como en Quito, predominaban los que se generaban en el ángulo formado por los templos y sus dependencias o las dependencias conventuales (Recuérdense en el caso quiteño los atrios de San Agustín, La Merced, La Compañía, etc.).

El plano de Darquea limitaba considerablemente la escenografía y acentuaba la perspectiva. La limitación escenográfica la consiguió con la proyección de las calles axiales a la plaza, que desembocaban frente a las fachadas de los templos de las religiones y del hospital, pero que no permitían una visión completa de las mismas y ponían freno a los puntos de fuga. Se jugaba con el efecto sorpresa o de atracción, ya que la mirada era dirigida hacia un determinado punto, pero resultaba obligado desplazarse hacia ese punto para contemplar la totalidad de lo que en él podía hallarse. Esto, a su vez, le permitía destacar aquello que quería, como eran esas mismas fachadas de las iglesias, lo que fue muy frecuente en las planificaciones españolas de finales del XVIII (OLIVERAS, 1998: 87-89), pero sin restar ninguna importancia a la plaza mayor en contraposición con otros espacios (LÁMINA 14). Por tanto, frente a lo que ocurre con los dameros tradicionales de las ciudades hispanoamericanas, ahora se da una mayor importancia al aspecto visual, que se completaría con el embellecimiento de los límites de la ciudad.

La ciudad de Darquea, como ya dijimos, no era una ciudad dinámica, ya que su contorno estaba delimitado por una alameda que la separaba de los arrabales, de los que no sabemos que hiciese proyecto alguno. Evidentemente, en el plano de Riobamba no existía la muralla, pero sí la idea de límite como línea divisoria entre el casco urbano y los lugares extramuros, marcado todo ello por la mencionada alameda, lo que de alguna forma era oponerse al llamado <<progreso del error $>>$, puesto que el crecimiento quedaba definido y con ello los espacios en 
Lámina 11. La visión de Ezequiel del templo de Jerusalén. Castelion (1551). Lámina 12. Torre según el tratado de Francesco di Giorgio Martini.Siglo XV.
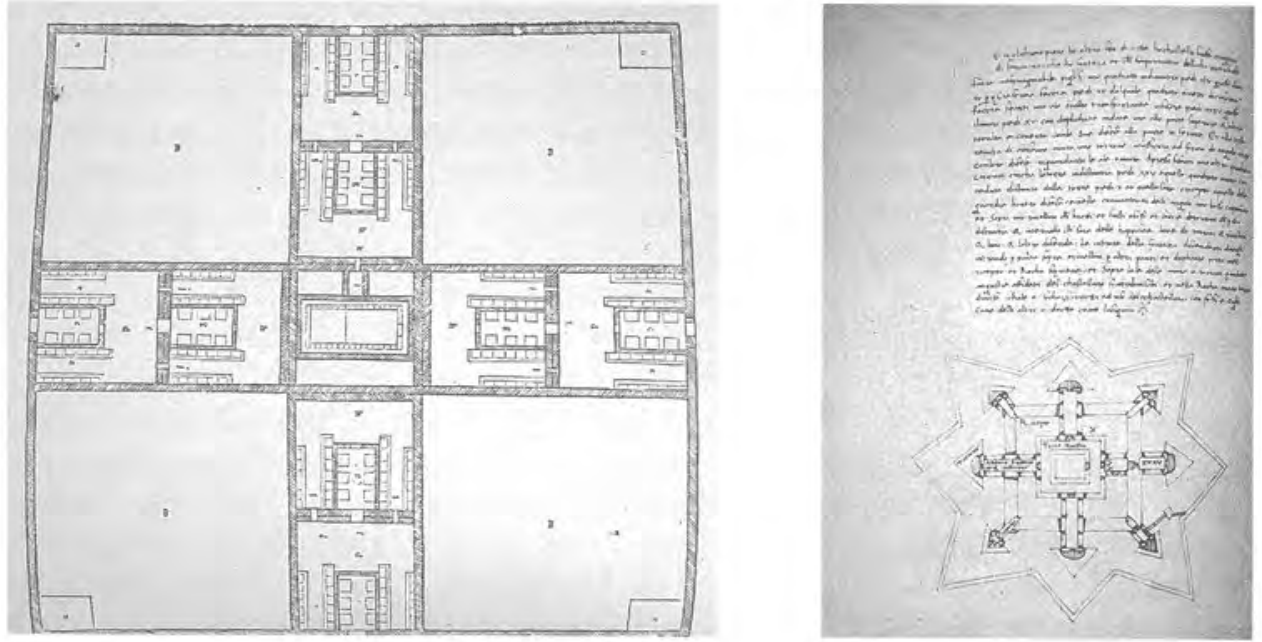

Lámina 13. Plano de la ciudad de Riobamba por Bernardo Darquea (1798). Lámina 14. Catedral y edificios de la plaza Mayor. Ciudad de Riobamba por Bernardo Darquea (1798).
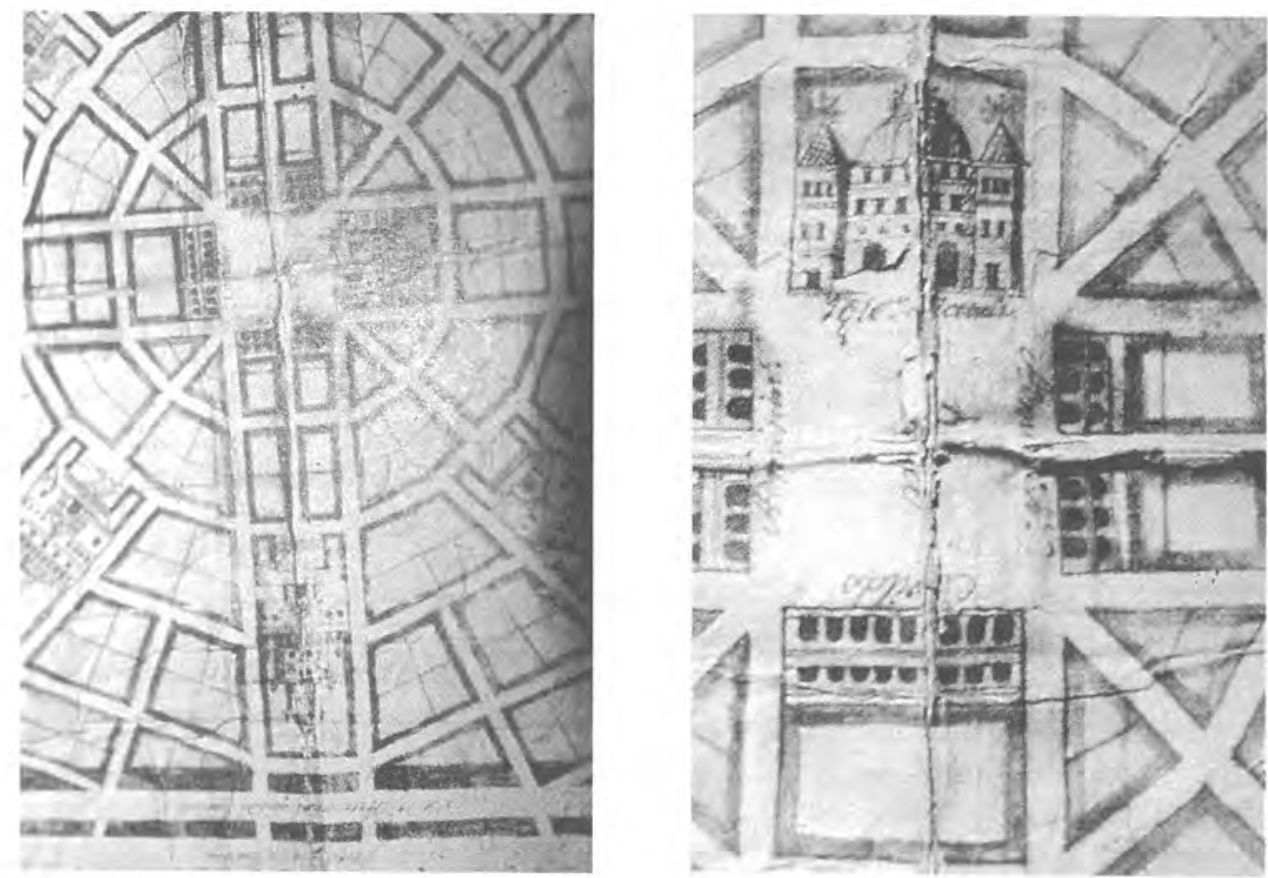
los que se debían ubicar los equipamientos (SAMBRICIO, 1991: 198). El proyecto de Riobamba, como ciudad de la Ilustración, al margen de otras connotaciones que pudiese haber, es el de una ciudad dialéctica, puesto que produce un fuerte y marcado contraste con su medio, a la vez que se convierte en el símbolo del mismo; es una ciudad que presenta aquella máxima de la Ilustración entre los cultos y los incultos; los primeros dirigen y ocupan el espacio intramuros, por tanto, son los que disfrutan del orden, mientras que los otros solo lo contemplan, porque el proyecto armónico de los ilustrados no implicaba la disolución de las diferencias sociales. De hecho, existe una frase de nuestro hombre, en este sentido, que puede ilustrar muy bien lo que decimos: Los pies nunca gobernaban la cabeza. Rompía así con una tradición propia del mundo hispanoamericano, tal y como le recordaron las autoridades quiteñas, pues las ciudades del interior eran abiertas, siempre con visos de expansionar su regularidad, sin rupturas en la planificación del conjunto, de modo que el mundo rural y el urbano se mezclaban en una línea difusa de delimitación, que permitía la integración de uno y otro medio en los extremos de las ciudades. Darquea, con sus límites, parece querer separar precisamente aquello que de rural tenían las poblaciones hispanoamericanas en sus contornos, de ahí que no proyectase ese territorio exterior, del que solo tuvo en cuenta la iglesia de San Blas que, probablemente por su sentido sagrado, la acerca al borde de la ciudad y la rodea de vegetación -la protege de la incultura-.

No hay que olvidar en todo esto la idea que refleja Olavide en El Evangelio del Triunfo (OLAVIDE, 1798), que algunos consideran como su Utopía. Ese ilustrado protector de Darquea planteaba una ciudad en cuyos límites se situaban las poblaciones de artesanos, intermedias con la diseminación del mundo rural. Darquea marcó con la alameda el límite entre naturaleza y ciudad, pero, a semejanza de lo que planteaba Olavide, su ciudad está rodeada por la calle de los artesanos, marcando ese límite que luego acentúa con las mencionadas alamedas, y que en el autor limeño estaría marcado por una muralla. Es cierto que, cuando nuestro hombre hizo su proyecto, no se había publicado la mencionada obra de Pablo de Olavide, pero, probablemente, en aquellas tertulias de La Carolina o en sus conversaciones más privadas, el limeño pudo haberle manifestado sus ideas, sobre todo si pensamos que se hallaban implicados en un proyecto de nuevas fundaciones.

Riobamaba nos presenta otro aspecto propio de una ciudad ilustrada al que ya hemos hecho mención: la inclusión en su planificación del mundo de la naturaleza. De hecho, la arborización fue casi una obsesión de los ilustrados. No olvidemos que, en 1774, es cuando Pristley descubrió el valor que las plantas tenían para la oxigenación de la atmósfera, aunque el interés del urbanismo por el embellecimiento vegetal era anterior. Las alamedas, tan propias del urbanismo del siglo XVIII, tuvieron una buena acogida en algunas ciudades hispanoamericanas, incluso en las de la Audiencia de Quito ${ }^{2}$. En el caso del proyecto de Riobamba, además de todo lo dicho, tenían un interés estético de acceso a la ciudad, de modo que su límite exterior, de alguna manera, tenía que reflejar su belleza interior, la belleza del mundo de los cultos. Era la imagen de la ciudad ante el mundo circundante, la

\footnotetext{
${ }^{2}$ Recordemos que por la misma época, por ejemplo, se proyecta otra alameda para la ciudad de Cuenca por el también ilustrado Juan López Tormaleo (PANIAGUA, 1988: 42).
} 
imagen del hombre civilizado, que acepta la naturaleza, pero que la transforma de acuerdo a sus cánones de belleza y lo hace, como era tradicional en la época, en la periferia del núcleo urbano, porque la belleza de la ciudad debía ir desde el exterior hacia el centro SAMBRICIO, 1988: 24). Así, Darquea rodea su plano de paseos arbolados, lo que además de embellecer la entrada de la población, servía para separar lo que de rural tenía el lugar en aquella época.

Al margen de las posibles influencias que podamos apreciar en esta obra, se nos plantea la duda de si su autor no habría leído a Milizia ${ }^{3}$. Este tratadista italiano exigía en uno de sus textos, como primordial, el orden para toda ciudad, pero al mismo tiempo hacía hincapié en el fenómeno de la variedad, la posibilidad de elección, la abundancia, etc. En realidad estaba abogando por eliminar la fría exactitud y uniformidad que se apreciaba en algunas ciudades, llamadas regulares, entre las que estarían muchas de las hispanoamericanas, incluso el proyecto de la Nueva Guatemala, que en 1776 realizó Luis Díez Navarro ${ }^{4}$. El orden de Milizia, como el de Darquea, no pasaban por la imagen repetitiva de figuras geométricas idénticas, sino que abogaban por un juego geométrico de alternancias que, siendo simétrico y ordenado, salvasen a las plantas urbanas de una tediosa regularidad.

La salubridad fue otra de las cuestiones que tuvo muy en cuenta Bernardo Darquea, como era común a muchos de los proyectos ilustrados, sobre todo durante el reinado de Carlos III. Pero la salubridad de Riobamaba se pudo afrontar desde sus inicios, como ciudad nueva que iba a ser, por ello ya el propio solar fue elegido en función de su conveniencia en este sentido: un lugar con buena ventilación, buena visión y la amplitud suficiente para permitir la expansión del entorno urbano. Todo ello sin olvidar lo que fue una obsesión de los ilustrados, el abastecimiento de aguas. Éste, según nos lo manifiesta nuestro hombre, estaba asegurado por la quebrada de Iguiscaguán y, en caso de que ésta no fuese suficiente, existía la posibilidad de recurrir a un río cercano y al abastecimiento de agua potable con algunas de las corrientes que bajaban del Chimborazo (AGI, Quito 384). Todo ello sin olvidar el abastecimiento de alimentos a la nueva ciudad con terrenos productivos en su entorno, que permitían una producción suficiente como para mantener a sus habitantes.

La necesidad de embellecimiento de las urbes, como ya hemos visto, estaba en la mente de todos los ilustrados. Darquea ya lo había tenido en cuenta en la reedificación de Ambato, la capital del corregimiento que él detentaba. Para aquel fin contó con la ayuda de algún particular, como don José Miguel Vallejo, vecino de Riobamba y abogado de la Audiencia, que, además de colaborar económicamente en la construcción de la iglesia mayor, donó 200 pesos para una pila de jaspe blanco, en la que pedía que fueran colocadas unas lápidas, con algunas inscripciones de versos en español, que fueran comprendidas por todos los habitantes. A esto habría que añadir, además de las alamedas, las columnas ornamentales que se proyectaron para los vértices del plano de la ciudad.

\footnotetext{
${ }^{3}$ (Milizia, 1768: 64). No olvidemos la transcendencia que las obras de este autor tuvieron en España, como lo refleja (SAMBRICIO, 131: 259-286).

${ }^{4}$ Aunque en Guatemala recurrió al plano tradicional de damero, observamos una cierta relación simbólica, pues las cuatro parroquias se ubican, de forma equidistante, en lo que serían las cuatro diagonales de la plaza mayor, amén de recurrir a la forma de cruz.
} 
En ese afán por el embellecimiento, existe algo en el plano de Bernardo Darquea, que no debemos pasar por alto: la arquitectura. Cierto es que no era un técnico en la materia y que sus construcciones no presentan grandes novedades, si las relacionamos con su plano. Sin embargo, a la postre, nos muestran algo de lo que un ilustrado tenía en mente a la hora de proyectar unos edificios en el conjunto de un entramado urbano. Ya dijimos que en la plaza mayor se concentraban la iglesia mayor, frente a ella el Cabildo, y, en los demás lados, otros edificios de la administración. El modelo de ubicación en sí, no tenía nada de novedoso para una ciudad hispanoamericanas y la disposición se mantenía en la tónica general de lo que se había proyectado para casi todas las ciudades desde su fundación, aunque en este caso se recurriese a la plaza porticada.

Los edificios civiles de la administración no presentan demasiadas novedades. Les caracteriza su sobriedad, con una galería de arcadas en la planta baja, que se repite a menor altura, en la segunda. En el edificio del cabildo ni siquiera queda resaltado el centro del mismo, como era tradicional en muchas de las construcciones de este tipo, con la introducción de escudos y símbolos alusivos a la monarquía hispánica o a la propia ciudad.

El otro edificio civil, el hospital, no nos permite saber que tipo de planta utiliza de las que estuvieron en boga en la época, aunque la disposición del mismo nos hace pensar en una planta longitudinal, sin mayores complicaciones, si tenemos en cuenta el espacio que utiliza. En su frente dispone de una fachada, semejante a la de las demás iglesias. Sin embargo, este edifico ocupa un lugar preferente en el conjunto, lo que parece querer reafirmar la idea cristiana de la caridad, como virtud principal que debía detentar el espíritu de toda ciudad.

Las edificaciones correspondientes a las órdenes religiosas ocupan dos cuadras cada una de ellas, por la necesidad que existía de disponer de un convento, en este caso, situado tras de la iglesia. La iglesia mayor, por el contrario, como edificación adscrita al clero secular, se limitaba a ocupar su cuadra privilegiada en la plaza mayor..

Especial mención merece la iglesia de San Blas, extramuros, que debía funcionar como parroquia de indios, en la que se recurrió a una arquitectura mucho más simple: una sola nave con cubierta a dos aguas y torre cuadrada, aneja al cuerpo del templo, que carece de toda ornamentación.

Parece, además, existir una contradicción entre la arquitectura y el urbanismo. Mientras el segundo podríamos considerarlo dentro de los cánones de la moda del momento, la primera parece mantener un claro apego a las tendencias barrocas, llegando en Santo Domingo a utilizarse, incluso, lo que parecen columnas salomónicas. La situación no era novedosa ni desconocida para Darquea, pues en el tiempo que él había vivido en España, y concretamente en Madrid, aun prevalecía la visión barroca del gran momento romano, como se prueba en San Francisco el Grande (CHUECA, 1989). De todos modos, aquel barroco español de última hora, muy influenciado por el italiano, había tenido una buena aceptación entre muchos ilustrados, ya que presentaba una versión cosmopolita, frente a lo que había sido el tradicional barroco español (SAMBRICIO, 1974: 15). Pero, además, en las nuevas poblaciones de Sierra Morena también apreciamos esa misma contradicción entre la arquitectura y el urbanismo, pues sigue prevaleciendo la apoteosis barroca, a pe- 
sar de la presencia de extranjeros y de ilustrados como directores de aquel proyecto. Darquea también se había podido dejar seducir por el tradicional barroco quiteño, de gusto clasicista y sin estridencias ornamentales en las fachadas, excepción hecha de la iglesia de la Compañía, lo que había alejado a aquel barroco de las corrientes limeñas o novohispanas.

Lo cierto es que nos encontramos con iglesias de fachadas en las que abundan los vanos para la ventilación, con una ornamentación muy limitada a la portada y con una planta en la que parece que existe cierta preferencia por las tres naves y por el crucero, éste cubierto casi siempre con una ampulosa cúpula con linterna. También utiliza torres en casi todos sus edificios religiosos.

En la arquitectura, lo mismo que en la planificación de la ciudad, existía un "dentro" y un "fuera". La iglesia mayor es la edificación de más envergadura, seguida en importancia y vistosidad por las iglesias de las órdenes religiosas, quedando San Blas como una construcción más simple, puesto que su uso debía estar dirigido a la población indígena. La arquitectura, pues, refleja la idea que de los hombres tenían muchos ilustrados y los pies y la cabeza de los que hablaba el propio Darquea, estableciendo rangos urbanos de acuerdo con las calidades de la población.

Desgraciadamente, como dijimos, nunca se aplicó el plano de Darquea y se optó por una ciudad regular, al modo tradicional del mundo hispanoamericano, tal y como lo deseaban las autoridades de la Real Audiencia.

\section{BIBLIOGRAFÍA.}

- AVILÉS, M. (1975): Sinapia: una utopía española del siglo de las luces, Madrid, Editora Nacional..

- ChueCA Goitia, F. (1989): «La personalidad artística de Sabatini», El Arte en tiempos de Carlos III, Madrid, CsIC.

- Jovellanos, M.G. (1984): Obras Completas II, Gijón, Ayuntamiento de Gijón.

- MARAVAll, J.A. (1991), Estudios de Historia del Pensamiento Español (siglo XVIII), Madrid, Mondadori.

- MARTINI, F. DI G. (1967): Trattati di architecttura ingegnaria e arti militare, Milán, Il Polifilo.

- MiliziA, F. (1768): La vita del piú celebri architetti di ogni tempo, Roma, (Edición anónima).

- OlaVIDE, P. DE (1798): El evangelio del triunfo o historia de un filósofo desengañado, Madrid, Imprenta de don Joseph Delgado.

- OLIVERAS SAMITIER, J. (1998): Nuevas poblaciones en la España de la Ilustración, Barcelona, Fundación Caja de Arquitectos.

- ORTIZ CRESPO, A. y PINO MARTÍNEZ, I. DEL (1997): «Ensayos de urbanismo barroco en la Audiencia de Quito», en R, GUTIÉRREZ: Barroco Iberoamericano de los Andes a las Pampas, Barcelona, Lunwerg.

- PANIAGUA PÉREZ, J. (1988): «Juan López Tormaleo y Joaquín Calderón, entre Astorga y América», Astorica 7.

- ROJAS, C. de (1598): Teoría y práctica de fortificación, Madrid, Biblioteca 
CEHOPU, (facsimil 1985).

- SAMBRICIO, C. (1975): «La teoría arquitectónica en José Ortiz Sanz “El Vitrubiano"», RIE 131.

--- (1988) «El amo de la Naturaleza», MOPU. Revista del Ministerio de Obras Públicas y Urbanismo 356.

--- (1991): Territorio y ciudad en la España de la Ilustración, Madrid, Ministerio de Obras Públicas y Transportes.

- VelasCO, J. de (1981): Historia del Reino de Quito, Caracas, Ed. Ayacucho.

RESUMEN: Tras el terremoto de 1797 en la ciudad de Riobamba (Ecuador), el francés Bernardo Darquea asumió la proyección de la nueva urbe, rompiendo con los esquemas tradicionales de la ciudad hispanoamericana en damero y optando por una planificación radial. Su nuevo proyecto estaba imbuido por las ideas ilustradas del siglo XVIII, pues no en vano había colaborado con Pablo de Olavide en las nuevas poblaciones de Sierra Morena y Andalucía. Sin embargo, su nueva ciudad poco tenía que ver con aquellos nuevos poblados y respondía más a las ideas de muchas de las planificaciones de la Europa del momento.

PALABRAS CLAVE: Urbanismo, Panificación, Hispanoamérica, Ecuador, Siglo XVIII.

ABSTRACT: After the city Riobamba (Ecuador) earthquake in 1797, the French Bernardo Darquea assumed the projection of the new metropolis by breaking with the traditional schemes of the checkerboard Spanish American city and choosing, instead, a radial planning. His new project was influenced by the illustrated ideas of XVIII century, as, not in vain, he had collaborated with Pablo de Olavide in the new cities of Sierra Morena and Andalusia. However his new city had nothing to do with those new cities and answered more to the ideas of many current European plannings.

KEY WORDS: City Planning, Projects, Spanish America, Ecuador, XVIII Century.

RÉSUMÉ: Après le tremblement de terre de 1797 de la ville de Riobamba (Equateur), le français Bernard Darquea assuma la responsabilité de la projection de la nouvelle cité, rompant les schémas traditionnels de la ville latino-américaine en damier et optant pour une planification radiale. Son nouveau projet était inspiré par les idées illustrées du $18^{\text {ème }}$ siècle, car ce n' est pas en vain qu'il avait collaboré avec Pablo de Olavide dans les nouvelles villes de Sierra Morena et d'Andalousie. Cependant, sa nouvelle ville n'avait pas grand chose à voir avec ces nouvelles agglomérations et répondait plus aux idées de nombreuses planifications de l'Europe de ce moment-là.

MOTS-CLÉS: Urbanisme, Projet, Amerique Latine, Equateur, XVIII ${ }^{\mathrm{EME}}$ Siecle. 